\title{
Safety Impact of Average Speed Control in the UK
}

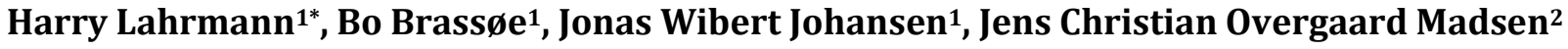 \\ ${ }^{1}$ Traffic Research Group, Department of Civil Engineering, Aalborg University, Aalborg, Denmark \\ ${ }^{2}$ Ramboll, Aarhus, Denmark \\ Email: ${ }^{\star h}$ sl@civil.aau.dk
}

How to cite this paper: Lahrmann, H., Brassøe, B., Johansen, J.W. and Madsen, J.C.O. (2016) Safety Impact of Average Speed Control in the UK. Journal of Transportation Technologies, 6, 312-326.

http://dx.doi.org/10.4236/jtts.2016.65028

Received: July 10, 2016

Accepted: September 25, 2016

Published: September 28, 2016

Copyright $\odot 2016$ by authors and Scientific Research Publishing Inc. This work is licensed under the Creative Commons Attribution International License (CC BY 4.0).

http://creativecommons.org/licenses/by/4.0/

\begin{abstract}
There is considerable safety potential in ensuring that motorists respect the speed limits. High speeds increase the number and severity of accidents. Technological development over the last 20 years has enabled the development of systems that allow automatic speed control. The first generation of automatic speed control was pointbased, but in recent years a potentially more effective alternative automatic speed control method has been introduced. This method is based upon records of drivers' average travel speed over selected sections of the road and is normally called average speed control or section control. This article discusses the different methods for automatic speed control and presents an evaluation of the safety effects of average speed control, documented through changes in speed levels and accidents before and after the implementation of average speed control at selected sites in the UK. The study demonstrates that the introduction of average speed control results in statistically significant and substantial reductions both in speed and in number of accidents. The evaluation indicates that average speed control has a higher safety effect than point-based automatic speed control.
\end{abstract}

\section{Keywords}

Average Speed Control, Fixed Speed Cameras, Automatic Speed Control, Safety Effect, UK

\section{Introduction}

It is well documented that there is a very strong correlation between vehicle speed and the number of fatalities and injuries in traffic [1]. Therefore, all Western countries introduced general speed limits on roads in the early 1970s. But modern cars are built for speed, and many perceive speed violation as a legitimate action [2]. Since the introduction of general speed limits, the challenge has then been to ensure that the speed limits are respected. In principle, observance of speed limits can be ensured in the following 
ways:

1) Roads can be designed so as to prevent drivers from exceeding the speed limits or to make driving at or below the speed limit feel natural [3].

2) Cars can be equipped with Intelligent Speed Adaptation systems which in various ways alert the driver if the speed limit is exceeded [4] [5].

3) Different types of campaigns can be implemented in order to motivate drivers to comply with speed limits [6].

4) Finally, drivers' speed can be controlled by enforcement. This type of control can be implemented as part of normal police controls/roadside checks, or by automatic speed control [7].

This article deals with the last-mentioned method-automatic speed control. The article first reviews two types of automatic speed cameras and their use, first Fixed Speed Cameras (FSC) and then Average Speed Control (ASC) - also called "section control" or "point-to-point" control. The effect of FSC is well documented, but the effect of ASC is far less documented. Therefore, we have implemented a study of the safety effect of ASC.

\subsection{Fixed Speed Cameras}

In the Nordic region, FSC was first introduced in Norway in 1988. The system consists of a so-called starling box which measures the speed of vehicles at a specific point on the road (Figure 1). If the speed is too high, the starling box takes a photo of the car and driver, and the photo is used for documentation when the fine is issued. The system is only active periodically, but motorists do not know when. For many years after its introduction, there were old-fashioned wet film cameras in the starling boxes, and these cameras were moved around among different stands. Today, FSC in Norway is provided with permanent digital cameras which transfer the photos to the police via wireless communication. The cameras are still not turned on permanently because the administrative processing of the images is quite expensive [8].

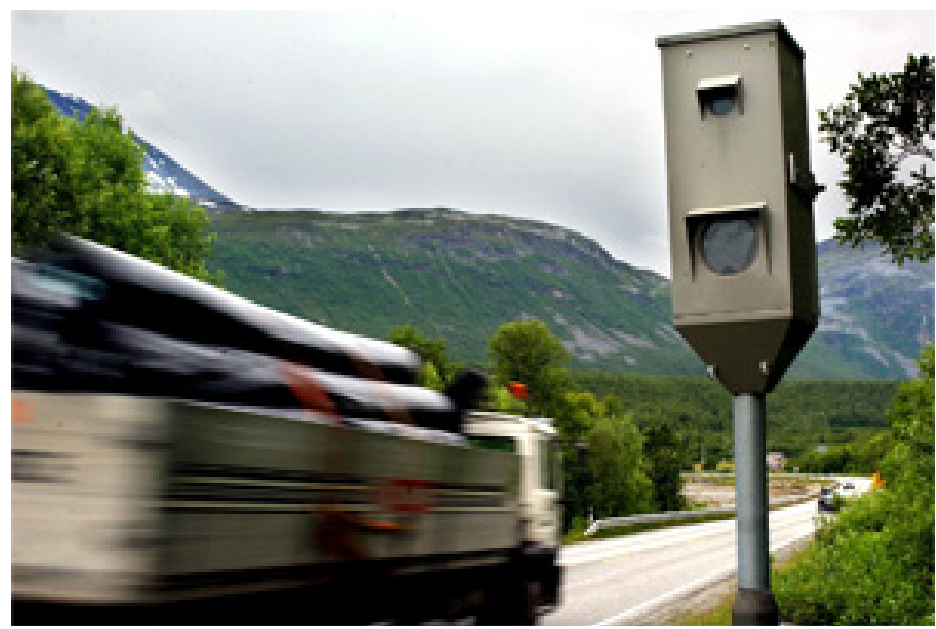

Figure 1. Starling box in Norway. 
Since 1988, FSC has been introduced in several European countries, including Sweden, Finland, England, Holland, Belgium and France. A large number of evaluation studies have shown good safety effects of the system [9]-[11].

In 2009, a one-year study with ten FSCs was completed in Denmark. After completion, the test was evaluated. In the evaluation, the effect on road users' speed was examined. In the direction with control, the average speed at the rural point with FSC decreased by $9.1 \mathrm{~km} / \mathrm{h}$ on weekdays (12\%) and by $12.1 \mathrm{~km} / \mathrm{h}$ at weekends (14\%). On urban roads, speed decreased slightly less, $10 \%$ and $13 \%$ respectively. Speed measurements a few hundred meters after the FSC locations showed that the effect had almost disappeared [12] [13]. FSC is typically placed on sections with increased accident risk. A section of some kilometres is posted with a sign telling the drivers that the section is photo monitored (see Figure 2), and the camera is placed at a random point of the section. The idea is that the road user should know that the section is monitored, but not exactly where and when, and thereby be encouraged to slow down at any time of day. The result has been that ever since the introduction of FSC drivers with local knowledge have made use of "kangaroo driving"-behaviour where speed is decreased slightly before the camera and increased again immediately after [14]. Today, kangaroo driving has become possible for all road users as the exact position of the FSC has been downloaded onto navigation devices. This allows all users simply just to slow down seconds before passing the camera [15].

\subsection{Average Speed Control}

To counter the trend of navigation devices alerting motorists a few seconds before the passage of FSC, the result being kangaroo driving behaviour, a different method for automatic speed control has been developed in recent years. The technique of average speed control (ASC) is that the time of the car's passage of two points at, e.g., 3 - $5 \mathrm{~km}$ intervals is recorded, and afterwards the car's average speed on the section between the two points is calculated (see Figure 3).

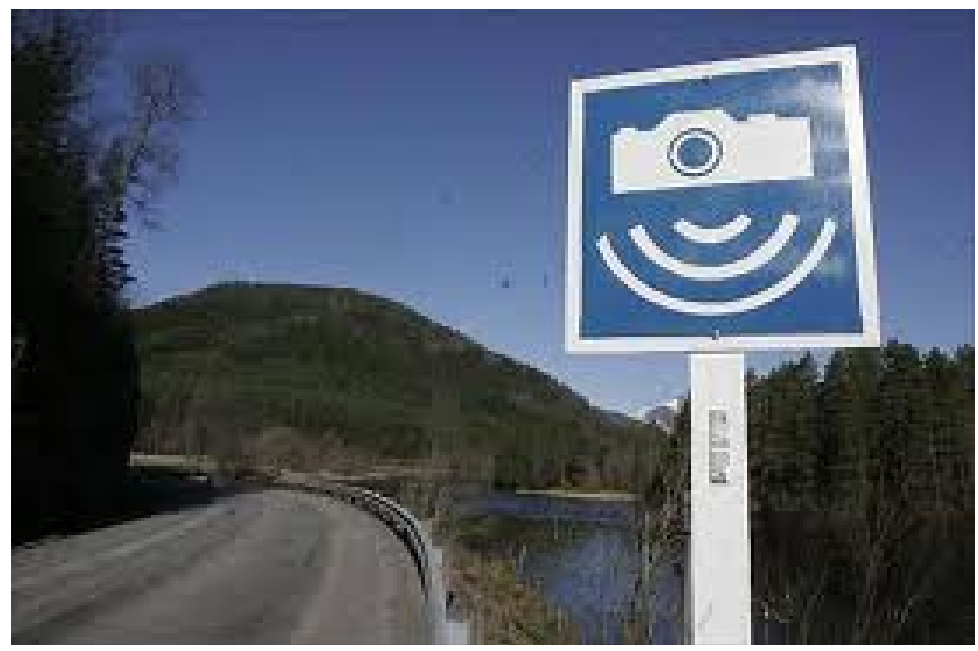

Figure 2. Road sections with FSC is in Norway are marked with this sign. 


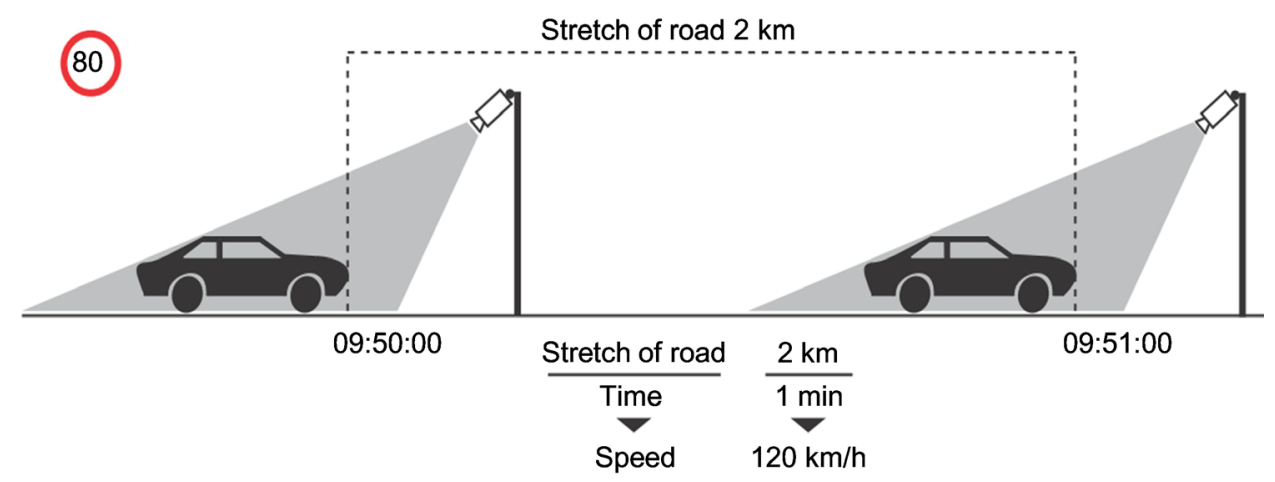

Figure 3. With average speed control (ASC), the car is photographed and time stamped in two points and the speed is calculated.

Technically, the system consists of a video camera located at two points taking photos of the passing cars and time stamping the photos. By means of image analysis software, the license plates are read automatically, making it possible to compare the license plates at the two points. This makes it possible to find cars that have driven the section at a higher average speed than the speed limit, and a fine can be automatically issued to the car owner. The fact that the control is linked to the average section speed minimizes the risks of speeding and discourages kangaroo driving, because the latter will not reduce travel time. Speeds above the speed limit at some points must necessarily be counterbalanced by speeds below the speed limit at other points, if a fine is to be avoided. Consequently, the implementation of ASC is guided by the hypothesis that such a system would lead to both smoother driving and larger speed reductions-and thus larger accident and injury reductions than FSC.

Today, ASC has been implemented in varying degrees in countries like the Norway, Netherlands, Austria, Italy and UK.

\subsubsection{Norway}

In Norway, ASC has been installed at two sites in 2009 and at 18 additional sites by 2013. About half of all ASC are in tunnels, most of which are undersea tunnels. Most ASC in tunnels are between the entrance and the bottom of the tunnel in the downhill direction. An evaluation of 14 of these sites found a non-significant reduction by $12 \%$ for injury crashes. The number of killed or severely injured was found to be significantly reduced by $49 \%$ [16].

\subsubsection{The Netherlands}

In the Netherlands, ASC is imposed on a number of roads, primarily motorways [17]. The system was first introduced in 2001 on E19 between Rotterdam and Delft at the same time as a lower speed limit of $80 \mathrm{~km} / \mathrm{h}$ was introduced. The effect was that the proportion of speeds over the limit was reduced to below $0.5 \%$ and the number of fatalities was reduced by more than $50 \%$. Motorists regarded the ASC a more fair automatic speed control than FSC where one can get caught up in short-term infringements, for example when overtaking [18] [19]. 


\subsubsection{Austria}

In Austria, the first system with ASC was set up in a tunnel in Vienna in 2003. Again, the effects on speeds were significant: Passenger car speeds decreased by $10 \mathrm{~km} / \mathrm{h}$ during the day and $20 \mathrm{~km} / \mathrm{h}$ at night, the trucks at by $15 \mathrm{~km} / \mathrm{h}$ during the day and $20 \mathrm{~km} / \mathrm{h}$ at night. The number of serious accidents was halved, but the numbers are small, so statistically significant effects were not obtained [20]. Today, there are four motorways with permanent ASC in Austria and two sections with temporary ASC in connection with a major road work [21].

\subsubsection{Italy}

Italy began with ASC in 2004, and today there are ASCs at no less than $2500 \mathrm{~km}$ of motorways corresponding to $37 \%$ of the highway network in Italy. There is between 10 and $25 \mathrm{~km}$ between the measuring points. The first effect studies showed a reduction by $15 \%$ in average speeds, by $51 \%$ in the number of fatalities and by $27 \%$ in the number of injured [3] [22]. At the same time, half of the traffic police force previously allocated to speed enforcement on the motorway network was transferred to the other networks; among other things, allowing the number of alcohol controls to be increased from 200,000 in 2006 to $1.5 \mathrm{~m}$ in 2009 [23].

\subsubsection{UK}

In 2000, the first ASC in the UK was introduced in Nottinghamshire. Since then, the system has expanded considerably. The first two locations in Nottinghamshire were selected because there was a very high rate of fatalities and serious injuries. High number of accidents and high severity were among the main requirements, originally defined by the Department for Transport, that were to be fulfilled for a local implementation of ASC to be allowed [24]. Since then, the requirements have been relaxed and automatic speed controls can now also be used to solve other problems than pure road safety problems. The supplier of equipment to ASC, Vysionics Intelligent Traffic Solutions, have published a number of so-called naive effect studies based on a simple comparison between the number of accidents before and after on their website. These studies show effects of well over $50 \%$ fewer deaths and serious injuries [25].

\section{Objective}

ASC is currently used in a number of countries, and ASC apparently affects speeds and accident figures positively. However, there is not, in relation to the knowledge of the authors of this paper, conducted more systematic effect studies of ASC, and hence there is still uncertainty on the effect of ASC compared to e.g. FSC.

This project aims to comply with the request for better documentation by analysing the effects of ASC on speed and road safety in the UK. The fact that speed control is carried out on the basis of the average travel speed of the individual driver-average section speed between measuring points on a section-gives rise to the hypothesis that speed reductions will not be restricted to short subsections at the points of registration, but will be imposed throughout the monitored road section. If this is the case, the safety 
effects will also take effect over a larger part of the road network and thus, ceteris paribus, lead to larger reductions in the number of people killed or injured in traffic.

\section{Design of the Analysis}

This study is conducted on the basis of experiences from the UK due to the possibility of collecting extensive before and after data on UK speeds and accidents.

\section{Calculation of Impact}

In the study, the evaluation of ASC is based on both changes in speed levels as well as changes in the number of accidents. The latter represents the classical approach to the compilation of safety effects. The choice of complementing the analysis of number of accidents with changes in the speed level is justified by the fact that ASC is aimed precisely at lowering the speed level, and that the relationship between speed and accidents is well documented [1]. Furthermore, regression to the mean is a less likely source of error in evaluations based on changes in speed rather than on changes in the number of accidents or the number of fatalities and injuries. Finally, the calculation of effects on both speeds and accidents contributes to strengthening the validity of the evaluation.

In order to document the effects on vehicle speed and the number of accidents, relevant statistical tests have been carried out, as explained below. In all statistical analysis, a significance level of 0.05 has been applied. This choice is consistent with current practice for impact studies (see e.g. [26]).

Common to both studies on speed and on accidents is that data from both a before period and an after period must be involved. For speed survey, the period length is not critical, provided that many vehicles have been recorded. For the accident investigation, we have opted for a period length of minimum three and maximum five years before and after implementation. Both types of studies require that there are no other significant site-specific changes that may affect speed levels and accident counts from before to after the ASC implementation. Otherwise it will not be possible to isolate the effects of ASC.

\section{Analyses}

The speed-based analysis has been conducted using speed data from a $54 \mathrm{~km}$ section of the A77 highway located in open country between Symington and Ardwell Bay in western Scotland. On the said section, 6 points for speed measurement were established, spread evenly over the section. At the points, speed was measured before and after the ASC implementation. A77 includes both 2 - and 4-lane sections, speed limits vary from $60 \mathrm{mph}(96.6 \mathrm{~km} / \mathrm{h})$ to $70 \mathrm{mph}(112.7 \mathrm{~km} / \mathrm{h})$, while annual average daily traffic (AADT) varies from 3,600 vehicles/day to 33,800 vehicles/day. The measuring stations were positioned to cover the respective types of sections along the A77.

The accident analysis was conducted on the basis of before-after accident data from 10 roads in and outside the urban area in Nottingham and Nottinghamshire in the East Midlands of England. The number of lanes varies from 2 to 4 , speed limits vary from 30 
mph $(48.3 \mathrm{~km} / \mathrm{h})$ to $60 \mathrm{mph}(96.6 \mathrm{~km} / \mathrm{h})$ and AADT varies from 8,000 to 38,000 vehicles/day.

Finally, it was decided to create a separate impact study of speeds and accidents on the A14 between Huntingdon and Cambridge in eastern England. On this 14-kilometer section, which is divided into 6 minor sections with ASC, FSC was initially implemented, but was subsequently replaced with ASC. The replacement was based on the assumption that further improvements in road safety could thus be achieved. If the transition from FSC to ASC can be shown to have resulted in significant improvements in road safety, it follows that the safety potential related to ASC exceeds the potential associated with FSC.

The analysis subsequently consists of three elements; an analysis of the effect of ASC on speed, an analysis of the effect of ASC on accidents and an analysis of the safety effects achieved by changing from FCS to ASC. It should be emphasized that the geographic locations in the three analyzes are different.

\section{Speed Analysis}

The opportunities to implement statistical tests on the speed data depend largely on the form in which this data is available. Data on individual vehicle level is sufficient for the best analysis options; such data provides the opportunity to implement statistical tests to changes in both mean speed and standard deviation. In the present case, it has not been possible to identify sites where before and after speed measurements on individual vehicle level have been made.

Ideally, the effects of ASC have to be measured on the basis of changes in drivers' average section speed from before to after. For A77, however, it has only been possible to obtain point speed measurements for both before and after period for six stations. For those six stations, there is the following information: 1) Point mean speed $(\bar{V}), 2)$ Number of vehicles during the registration period $(n)$ and 3 ) standard deviation (S) divided by different weeks before and after the implementation of ASC. In order to examine whether changes in speeds from before to after were significant, it was chosen to estimate the $95 \%$-confidence interval around the calculated mean speeds before and after according to the formula [27]:

$$
\bar{V}-1.96 * \frac{S}{\sqrt{n-1}}<\mu<\bar{V}+1.96 * \frac{S}{\sqrt{n-1}}
$$

whether there has been a significant change in average mean speeds from before to after is investigated by comparing the confidence intervals for point mean speeds before and after the ASC implementation. If the upper limit of the confidence interval is below the lower limit of the confidence interval before, there has been a significant decrease in point mean speed.

\section{Results}

Table 1 shows the results of speed tests for the monitoring stations at six different locations in Scotland. Measurements were made on sites which were independent of the 
Table 1. Change in the mean speeds in 6 points of A77 based on approx. 5.5 million vehicles before measurements and 32.5 million vehicles in the after measurements.

\begin{tabular}{|c|c|c|c|c|c|}
\hline & $\begin{array}{c}\text { Before ASC } \\
\text { (mph) }\end{array}$ & $\begin{array}{l}\text { During ASC } \\
(\mathrm{mph})\end{array}$ & $\begin{array}{l}\text { Change } \\
\text { (mph) }\end{array}$ & $\begin{array}{l}\text { Change in } \\
\text { percent }\end{array}$ & Conclusion \\
\hline Symington (70 mph) & 63.9 & 59.6 & -4.3 & $-6,7$ & Statistically significant decrease \\
\hline Girvan Mains (60 mph) & 51.7 & 49.4 & -2.3 & -4.5 & Statistically significant decrease \\
\hline Balkenna (60 mph) & 53.3 & 50.0 & -3.4 & -6.3 & Statistically significant decrease \\
\hline Minishant (60 mph) & 49.3 & 39.5 & -9.8 & -19.8 & Statistically significant decrease \\
\hline Ardwell Bay (60 mph) & 52.9 & 49.0 & -3.9 & -7.3 & Statistically significant decrease \\
\hline Between B7038 og B730 (60 mph) & 63.0 & 61.6 & -1.4 & -2.2 & Statistically significant decrease \\
\hline Average & 55.7 & 51.5 & 4.2 & -7.5 & \\
\hline
\end{tabular}

location of the poles for the distance-based speed control. The data was collected in a variable period during the before period of between 1 and 13 weeks and in an after period of 50 weeks.

Table 1 shows a statistically significant decrease in all point mean speeds from before to after. The reductions are in the range of $1.4 \mathrm{mph}$ to $9.8 \mathrm{mph}(2.2 \mathrm{~km} / \mathrm{h}$ to $15.7 \mathrm{~km} / \mathrm{h})$. At one of the sites, we see a significant decline below the speed limit. This may be evidence of congestion on that site, but it is not known explicitly.

The estimated mean average speeds over the six stations before and after were 55.7 $\mathrm{mph}$ and $51.5 \mathrm{mph}$ respectively, yielding a speed reduction of $4.2 \mathrm{mph}(6.7 \mathrm{~km} / \mathrm{h})$ and hence a decrease of $7.5 \%$.

The fact that there is a significant decrease in mean speed at all measurement points indicates that the ASC affects the speed levels across the whole section length and, consequently, the reduction in average mean speed can be seen as an exponent of the ASC effect on mean travel speed across the line. According to the Power Model, decreasing the average mean speed on rural roads by $7.5 \%$ can be expected to result in a decrease of $11.7 \%$ in the number of injury accidents, $18.3 \%$ in the number of serious injury accidents and $27.4 \%$ in the number of fatal accidents [1].

\section{Accident Analysis}

To establish whether a statistically significant reduction in the number of accidents can be documented, a statistical analysis of changes in the number of accidents was conducted. The analysis was carried out on the basis of the recorded number of injury accidents before and after the implementation of the ten ASC sites in Nottingham and Nottinghamshire.

To positively identify the real safety effects, the site-specific expected number of accidents in the period $T$ with the initiative implemented $\left(\mu_{i T \text {,with }}\right)$ is compared to the site-specific expected number of accidents as it would have been during the same period without the measure implemented $\left(\mu_{i T \text {,without }}\right)$. Neither of these quantities is ob- 
servable/measurable. Instead, the observed number of accidents in the after period is used as a proxy for $\mu_{i T \text {, with }}$, while the observed number of accidents in the before period is used as a basis for estimating $\mu_{i T \text {,without }}$ To check for the portion of the change in number of accidents caused by general trends in traffic safety as well as local changes in traffic volumes, the number of accidents in the before period is extrapolated using the correction factors $C_{\text {Trend }}$ and $C_{\text {Traffic }}$ These are estimated from changes in the number of accidents in English reference sites of the same type and with the same speed limit, respectively, on the basis of accident models describing changes in the number of accidents due to local changes in traffic volumes.

The evaluation is thus based on the following basic formula [27]:

$$
\varepsilon_{\text {rel }, j}=\frac{X_{j a}}{X_{j b} * C_{\text {Trend }} * C_{\text {Traffic }}}
$$

where:

$\mathcal{\varepsilon}_{\text {rel, } ;}:$ The relative accident effect on the site $j$,

$X_{j a}$ : The number of accidents at a location $j$, in the after period,

$X_{j b}$ : The number of accidents at a location $j$, in the before period,

$C_{\text {Trend }}$ : Correction factor for general accident development,

$C_{\text {Traffic }}$ Correction factor for changed traffic volume.

As the number of accidents vary randomly over time, the changes in the number of accidents from before to after need to be corrected for random variation. Such correction is particularly relevant in this case since the sites were selected for ASC due to abnormally high accident occurrences in the before period. This would indicate that part of the change in accident occurrence from before to after is due to accidents dropping from a randomly high level to a level closer to or below normal. This phenomenon is called "regression to the mean effect". Failure to check for this phenomenon is likely to result in overestimating the safety effect of the initiative. The empirical Bayes method is the best way of checking for regression to the mean effect [27]. Unfortunately, the required accident models using empirical Bayes method were not available for the UK road network.

Instead, attempts were made in two ways to take some account of regression to the mean effect. First, by testing whether the changes in the number of accidents from before to after at the individual sites are likely to be entirely random or not, the statistical significance test was implemented in accordance with the 1981 Danish Road Directorate's guidance in accident-based evaluation studies [28]. The test uses a significance level of $95 \%$ and helps assessing whether or not it is probable that the measurement has affected road safety. In contrast to the empirical Bayes method, the test is unfortunately not able to correct the estimate of the safety effect for regression to the mean effect. Furthermore, in assessing the overall safety effects of ASC, the year with the highest accident observation in the before period and the year with the lowest accident observation in the after period of the analysis were left out in order to obtain a more conservative estimate of the safety effect of the ASC (see e.g. [29] [30]). 


\section{Results}

Table 2 shows the estimates of the local safety effects. For all sites, the number of injury accidents is reduced from before to after. However, only in 4 out of 10 sites, the change can be linked to a positive safety impact of ASC. In the remaining 6 cases, the statistical test shows that it cannot be excluded that the changes in the number of accidents from before to after might be purely random.

To obtain an overall estimate of safety effects of ASC, a meta-analysis was carried out in accordance with the Log Odds Method (see [14]). The Log Odds method allows, first, to make an estimate of the expected effect on the number of accidents and, second, it provides the opportunity to establish whether the safety effect varies statistically significant between individual sites.

The expected effect of the measure is estimated as a weighted average of the estimated site-specific effects, in this case the 10 sites included in the accident analysis. Mean effect is estimated according to the equation:

$$
\bar{y}=\exp \left(\frac{\sum_{j=1}^{g} w_{j} y_{j}}{\sum_{j=1}^{g} w_{j}}\right) .
$$

$y_{i}$ is the natural logarithm of the estimated site-specific effect of location $j$, and $w_{j}$ is a statistical weight attached to the site-specific effect of location $j$. To examine whether the change in accident occurrence is significant and to describe the uncertainty of the estimate of the expected safety effect, the confidence interval of $\bar{y}$ is estimated by:

$$
95 \% \text { confidence interval (upper and lower })=\exp \left[\left(\frac{\sum_{j}^{g} w_{j} y_{j}}{\sum_{j}^{g} w_{j}}\right) \pm 1.96 \cdot\left(\frac{1}{\sqrt{\sum_{j}^{g} w_{j}}}\right)\right] \text {. }
$$

Table 2. Results from the accident analysis for injury accidents.

\begin{tabular}{cccccc}
\hline & Before & After & Expected after & Change & Statistically significant effect \\
\hline Edwards Lane & 14 & 6 & 11 & $-57 \%$ & No \\
A6514 Ring Road & 302 & 183 & 284 & $-39 \%$ & Yes \\
B6004 Arnold Road & 75 & 31 & 65 & $-59 \%$ & Yes \\
A610 Nuthall Road & 108 & 47 & 89 & $-56 \%$ & Yes \\
A46 Cotgrave & 44 & 24 & 32 & $-45 \%$ & No \\
A46 Fosse Road & 27 & 25 & 23 & $-7 \%$ & No \\
A52 Bingham & 20 & 15 & 15 & $-25 \%$ & No \\
A52 Radcliffe & 44 & 38 & 35 & $-14 \%$ & No \\
A52 Saxondale & 33 & 21 & 28 & $-36 \%$ & No \\
A631 Scaftworth & 8 & 1 & 8 & $-88 \%$ & Yes
\end{tabular}


The statistical weight, $w_{p}$, was estimated on the basis of the observed number of accidents before and after on the individual sites and the observed number of accidents on the respective reference sites. The method to estimate $w_{j}$ depends on whether or not there is evidence of effect homogeneity between the sites. Consequently, the statistical tests for homogeneity of variances were conducted according to [31]. These tests show that there is effect homogeneity when all accidents are included, reflecting the fact that the safety effect does not vary between sites. The variations in the estimated site-specific effects (see Table 2), can be interpreted as random. Consequently, the meta-analysis with all accidents included was carried out using a fixed effects model (see [32]). In the adjusted analysis, from which the worst year before and the best year after were omitted, the statistical test indicated that the effects are heterogeneous. Hence, in this case the meta-analysis is based on a random-effects model.

If the confidence interval contains the value 1, corresponding to "no effect", the effect of the actual measure is not significant. If the lower limit of the confidence interval is above 1.0, the evaluated measure has a negative safety impact. If the upper limit of the confidence interval is below 1.0, the measure has a positive safety impact. The meta-analysis was performed by including the number of accidents for all years in the before and after periods respectively and by excluding the number of accidents in the worst year before and the best year after (corrected accident figures). The result is shown in Table 3.

Both analyses indicate a statistically significant positive safety effect of the introduction of ASC. If all accidents before and after are included, the expected effect on the number of injury accidents is a reduction by 33\%. As a result of the lack of control for regression to the mean effect, the safety effect is probably overestimated. If the worst accident year is excluded from the before period and the best accident year left out from the after period, the expected effect is a reduction of $24 \%$ in the number of injury accidents. The expected effect will vary within the range $-9 \%$ to $-36 \%$.

The test conducted for effect homogeneity shows that the effect of introducing ASC tends to vary between sites. The data is too limited to clarify the factors that could justify such a variation in the local safety effect. Possible explanations for these variations could be differences in speed limits and the detailed road design and speed level prior to the ASC implementation.

Table 3. Meta-analysis effects of injury accidents. If the interval is less than 1, a significant safety impact can be identified.

\begin{tabular}{ccc}
\hline & All accidents & Corrected accident figures \\
\hline Expected effect & 0.67 & 0.76 \\
95\%-CI lower & 0.59 & 0.64 \\
$95 \%-C I$ upper & 0.76 & 0.91 \\
Conclusion & Statistically significant effect & Statistically significant effect \\
Used model & Fixed-effect & Random-effect \\
\hline
\end{tabular}




\section{From FSC to ASC}

A14 between Cambridge and Huntingdon in the East of England has been the subject of a separate study, as it is possible to study the safety effects associated with the transition from FSC to ASC on this location. In 2001, FSC was established in eight points in an attempt to reduce the number of accidents and fatalities on the $22 \mathrm{~km}$ long stretch. Despite this measure, many serious accidents still occurred on the location. Hence ASC was established in 2007 in a new effort to reduce the number of accidents [25].

In this project, we have performed an analysis of the speed data from six sites on A14 using the Chi-square test. At all test sites, there has been a significant change in speed levels after the transition to ASC. Figure 4 shows the distribution of vehicles within speed intervals. The distribution was calculated as an average of the results from six Chi-tests corresponding to the six measurement points on the A14. The figure shows a decrease in the speed level and a reduced dispersion in speeds.

When analysed on the number of injury accidents, the number dropped from 246 accidents in the three years with the FSC to 173 accidents in the three years with ASC, corresponding to a reduction of almost $30 \%$. This reduction, however, is not significant. If we consider serious injury accidents and fatal and severe injury accidents only, there is a significant reduction of 63\%; 43 serious injury accidents during the period of FSC and 16 serious injury accidents in the period of ASC. Regression to the mean effect cannot be excluded as a possible source of error in this outcome. Still, the analysis combined with the documented decrease in speed level suggests that, as compared with FSC, the ASC implementation gives rise to improved road safety. The explanation for this improvement of road safety should be sought in the fact that the effects on the accident rate apply to the whole stretch of road and are not limited to sections immediately before and after FSC points.

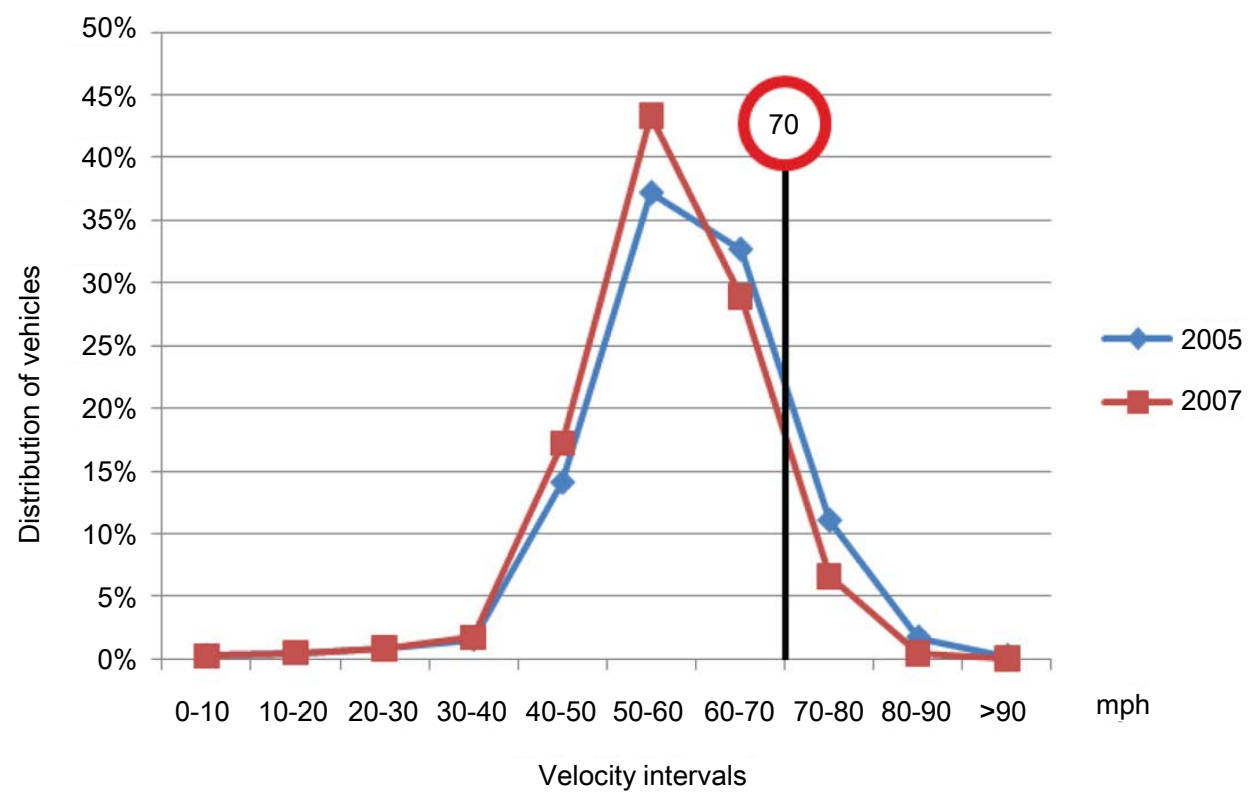

Figure 4. Distribution of the proportion of vehicles in velocity intervals from Cambridge. 


\section{Conclusions and Prospects}

This evaluation of ASC in the UK is based on both speed data and accident data from periods before and after the implementation of ASC and this documents that the ASC has a significant positive safety impact. Speed is reduced by $7.5 \%$, and accident analyses indicate reductions in the number of serious injury accidents of $9 \%$ to $41 \%$. Since it has not been possible to conduct a proper verification of the regression to the mean effect, the expected effect on the number of injury accidents is probably a reduction in the range of $10 \%$ to $20 \%$. The evaluation carried out on the number of accidents indicates that the introduction of ASC in particular reduces the incidence of serious injury accidents and fatalities, which are in line with the documented relationships between speeds and the number of accidents and injuries (see [1]). Specifically, further analysis of the safety effects shows that the number of serious injury accidents, including fatal accidents, is significantly reduced in the order of $20 \%$ to $30 \%$. Similar conclusions can be found in the Norwegian evaluations of a trial with ASC [16] [33].

In summary, the above-mentioned studies reflect that FSC has a marked effect on the number of accidents in short sections, while ASC reduces travel speeds over longer stretches of road. This suggests that the implementation of ASC is likely to result in a greater reduction in the number of people killed and injured in road traffic than FSC. In addition, ASC appears to eliminate the incentive for kangaroo driving whereas FSC rather seems to encourage this, especially considering the fact that any driver with the intention of speeding is likely to receive a warning from a navigation device seconds before passing an FSC stand.

As a result, ASC holds significant potential to reduce speeds on contiguous stretches of road in rural areas where traffic accidents are typically of high severity. Due to the geographically limited effect of FSC, the safety potential seems to attach itself to defined sections with local velocity and/or accident issues, including for example black spots.

\section{Acknowledgements}

Warm thanks to Geoff Collins in Vysionics Intelligent Traffic Solutions, who helped us contact a wide range of road authorities in the UK who has installed ASC. Without his help it would not have been possible for us to collect the comprehensive data that underlies the estimates in this article of the effect of ASC on both speed and accidents.

\section{References}

[1] Elvik, R. (2009) The Power Model of the Relationship between Speed and Road Safety, Update and New Analyses. Institute of Transport Economics, Oslo.

[2] Jensen, A.K., Frydkjær, T. and Fisker, L. (2011) Trafiksikkerhed ifølge danskerne-5 paradokser om sprit og fart i trafikken. TrygFonden and Mandag Morgen. (In Danish)

[3] ETSC (2008) Road Safety Performance Index, Reducing Deaths on Motorways. European Traffic Safety Council, European Commission, Mobility and Transport, Road Safety.

http://ec.europa.eu/transport/road_safety/specialist/knowledge/speed/speed_limits/road_en gineering_en.htm

[4] Lahrmann, H., et al. (2012) Pay as You Speed, ISA with Incentives for Not Speeding: A Case 
of Test Driver Recruitment. Accident Analysis \& Prevention, 48, 10-16. http://www.sciencedirect.com/science/article/pii/S0001457511000650

[5] Lahrmann, H., et al. (2012) Pay as You Speed, ISA with Incentive for Not Speeding: Results and Interpretation of Speed Data. Accident Analysis \& Prevention, 48, 17-28. http://www.sciencedirect.com/science/article/pii/S0001457511000662

[6] Delhomme, P., et al. (1999) Evaluated Road Safety Campaigns: an Overview of 265 Campaigns and Some Meta-Analysis on Accidents. In: Guiding Automobilists through Technology \& Education, European Commission, Brussels.

[7] Lynam, D., et al. (2005) SUNflower+6-An Extended Study of the Development of Road Safety in Sweden, the United Kingdom and the Netherlands. Transport Research Laboratory, Crowthorne.

[8] Elvik, R. (2010) Utviklingen i oppdagelsesrisiko for trafikkforseelser. TØI-Rapport 1059/ 2010. (In Norwegian)

[9] Thomas, L., et al. (2008) Safety Effects of Automated Speed Enforcement Programs; Critical Review of International Literature. Transportation Research Board, Transportation Research Record, No. 2078, 117-126. http://dx.doi.org/10.3141/2078-16

[10] Høye, A. (2014) Speed Cameras, Section Control, and Kangaroo Jumps-A Meta-Analysis. Accident Analysis \& Prevention, 73, 200-208. http://dx.doi.org/10.1016/j.aap.2014.09.001

[11] Høye, A. (2015B) Safety Effects of Fixed Speed Cameras-An Empirical Bayes Evaluation. Accident Analysis \& Prevention, 82, 263-269.

[12] Sørensen, H. (2010) Evaluering af ATK-forsøget, Stationær ATK’s virkning på trafikkens hastighed, Vejdirektoratet. (In Danish)

[13] Hels, T., et al. (2010) Automatisk hastighedskontrol-Vurdering af trafiksikkerhed og samfundsøkonomi. DTU Transport. (In Danish)

[14] Elvik, R. and Vaa, T. (2004) The Handbook of Road Safety Measures. Pergamon, Oslo.

[15] Tomtom Speed Cameras (2016). http://www.tomtom.com/en_gb/sat-nav/car-sat-nav/

[16] Høye, A. (2015) Safety Effects of Section Control-An Empirical Bayes Evaluation. Accident Analysis \& Prevention, 74, 169-178. http://dx.doi.org/10.1016/j.aap.2014.10.016

[17] Dutch Ministry of Justice (2016) https://www.om.nl/onderwerpen/verkeer/handhaving-verkeer/snelheid/trajectcontrole/

[18] Wegmann, F. and Goldenbeld, C. (2006) Speed Management, Enforcement and New Technologies. SWOV Institute for Road Safety Research, The Netherlands.

[19] SWOV (2008) Police Enforcement and Driving Speed. SWOV Fact Sheet, Leidschendam, the Netherlands.

[20] Stefan, C. (2006) Automatic Speed Enforcement in the Kaisermühler Tunnel (Vienna, A22 Motorway). Austian Road Safety Board (KfV).

[21] ASFINAG (2014) http://www.asfinag.at/en/unterwegs/verkehrssicherheit/massnahmen

[22] Autostrade (2016) https://www.autostrade.it/en/tecnologia-sicurezza/sicurezza/tutor

[23] Sardi, P.A. (2010) Mail from Pier Angelo Sardi, Società Italiana di Psicologia della Sicurezza Viaria, Italy.

[24] Department for Transport (2007) https://www.gov.uk/government/uploads/system/uploads/attachment_data/file/465165/dftcircular-0107.pdf

[25] Vysionics (2011) Read Traffic Management Systems \& ANPR Case Studies. http://www.vysionics.com/Download/ID/117/RowID/728/TableID/33 
[26] Madsen, J.C.O. (2005) Statistisk Uheldsteori og Sortpletudpegning-Sortpletarbejdets teoretiske grundlag, Trafikforskningsgruppen, Trafikforskningsgruppen. Aalborg Universitet, Aalborg. (In Danish)

[27] Dawson, B. and Trapp, R.G. (2001) Basic \& Clinical Biostatistics. Lange Medical Books/ McGraw-Hill, New York.

[28] Jørgensen, E. (1981) Sikkerhedsmæssig effekt, vejledning for vejbestyrelser. Vejdirektoratet, Copenhagen. (In Danish)

[29] Brüde, U. and Larsson, J. (1982) The Regression-to-Mean Effect. Proceedings of Seminar on Short-Term and Area-Wide Evaluation of Safety Measures, SWOV Institute for Road Safety Research, Leidschendam, 19-21 April 1982, 47-54.

[30] Lahrmann, H. and Holmskov, O. (1993) Er sortpletbekæmpelse vejen frem? Dansk Vejtidsskrift, Farsoe. (In Danish)

[31] Elvik, R. (2001) Area-Wide Urban Traffic Calming Schemes: A Meta-Analysis of Safety Effects. Accident Analysis and Prevention, 33, 327-336. http://dx.doi.org/10.1016/S0001-4575(00)00046-4

[32] Elvik, R. (2005) Introductory Guide to Systematic Reviews and Meta-Analysis, Transportation Research Board. Transportation Research Record, 1908, 230-235. http://dx.doi.org/10.3141/1908-28

[33] Ragnøy, A. (2011) Streknings-ATK: Resultat av Evaluering, Statens Vegvesen. VD Rapport 2011: 2625. (In Norwegian)

\section{Submit or recommend next manuscript to SCIRP and we will provide best service} for you:

Accepting pre-submission inquiries through Email, Facebook, LinkedIn, Twitter, etc. A wide selection of journals (inclusive of 9 subjects, more than 200 journals)

Providing 24-hour high-quality service

User-friendly online submission system

Fair and swift peer-review system

Efficient typesetting and proofreading procedure

Display of the result of downloads and visits, as well as the number of cited articles

Maximum dissemination of your research work

Submit your manuscript at: http://papersubmission.scirp.org/

Or contact jtts@scirp.org 